\title{
Clinical Results of Harms Technique in Atlantoaxial Instability Treatment
}

\author{
Durmuş Oğuz Karakoyun ${ }^{1}$ \\ ${ }^{1}$ Department of Neurosurgery, Ordu University School of Medicine, Ordu, Turkey
}

Received: 19 July 2020, Accepted: 14 November 2020, Published online: 31 December 2020

(C) Ordu University Institute of Health Sciences, Turkey, 2020

\begin{abstract}
Objective: The aim of this study is to present the clinical experience and results in the application of atlantoaxial stabilization performed with Harms technique to contribute to the literature.

Methods: Archive files of adult patients who underwent C1-2 stabilization using Harms technique with the diagnosis of atlantoaxial instability for 2015-2020 were examined. Clinical and radiological findings of 15 patients with at least 6 months of follow-up were evaluated. Preoperative clinical and radiological records, preoperative observations, postoperative complications, and clinical responses were evaluated.

Results: 15 patients included in the study; 10 were men and 5 were women. The age range was 25-82 (mean: 58.7). There were 6 patients (40.0\%) who had Anderson and D'Alanzo classification type 2 odontoid fracture 2 patients (13.3\%) with Jefferson fracture, 2 patients (13.3\%) with C2 extension type tear drop fracture, 2 patients $(13.3 \%)$ with narrowing in the level of craniocervical junction, 1 patient $(6.7 \%)$ with upper cervical region tumor and 2 patients (13.3\%) was in the form of hangmans fracture. Screw malposition was not observed in the postoperative period. Bone fusion developed in all patients after surgery. No vertebral artery damage or neurological damage was observed. Wound infection was not observed in any of these patients. Visual analog scale (VAS) reduction and Japanese orthopedic (JOA) scores were increased in all postoperative patients.

Conclusion: Surgery of atlantoaxial instability is a pathology requiring adequate surgical experience due to the complicated anatomical structure. Using the Harms technique, sufficient stability is provided with a low complication rate. With this method, improvement in the clinical findings of the patients and high bone fusion were obtained.
\end{abstract}

Key words: C1-2 screw fixation, cervical trauma, odontoid fracture.

Suggested Citation: Karakoyun DO. Clinical Results of Harms Technique in Atlantoaxial Instability Treatment. Middle Black Sea Journal of Health Science, 2020; 6(3):294-298.

Address for correspondence/reprints:

DOI: $\quad 10.19127 / \mathrm{mbsjohs.771475}$

Durmuş Oğuz Karakoyun

Telephone number: +90 (505) 6336577

ORCID-ID 0000-0002-1306-7584

E-mail:droguzk@gmail.com 


\section{Introduction}

The level of C1 (Atlas) and C2 (Axis) vertebrae, called upper cervical vertebrae, have a unique anatomical structure. There is no corpus, pedicle and spinous process on $\mathrm{C} 1$ vertebrae. In addition, there is odontoid process on $\mathrm{C} 2$ vertebrae different from other vertebras. Vertebral arteries traverse through the transverse vertebral foramen into the cranium through the posterior arch of $\mathrm{C} 1$ vertebrae. The axial load of the weight of skull is transferred from the occipital condyles to the masses of the $\mathrm{C} 1$ vertebra, and from there to the $\mathrm{C} 1-2$ facet joints and the $\mathrm{C} 2$ lareal masses. The load is then distributed to the subaxial region with the disc and facet joints of $\mathrm{C} 2-3$. The atlantoaxial joint consists of 4 synovial joints. The first one is between the back of the anterior arch of $\mathrm{C} 1$ vertebra and the dens and the second one is between the odontoid process and the transverse ligament. Two of them are between the facet joints on both sides (Chen et al., 2020). The atlantoaxial joint is the most mobile region of the spine and makes $38.9 \%$ of the axial rotation movement (Badhiwala et al., 2017). It also performs a small amount of flexionextension and lateral bending motion.

Approximately $25-35 \%$ of cervical fractures in an adult concern the first three cervical vertebrae. In these fractures, $45-60 \%$ neurological deficits can be encountered (Anderson and D'Alanzo, 1974- Çağlar et al., 2005). Due to upper cervical traumas (traffic accidents, falls from height, diving, etc.), instability may develop in the atlantoaxial joint. According to the classification made by Anderson and D'Alanzo, type 2 odontoid fractures are considered unstable (Anderson and D'Alanzo, 1974). In addition, it has been reported that $25 \%$ of patients with rheumatoid arthritis may have instability due to chronic inflammation (Kim and Hilibrand, 2005). It has also been reported that instability may develop with Marfan syndrome and Grisel's syndrome (Dagtekin et al., 2011). Regardless of the cause, atlantoaxial instability becomes an important mortality and morbidity problem (Isik et all., 2018). Neurological findings, radiological findings showing pressure and instability on neuronal structures, additional diseases and age that will affect morbidity are important in the planning of treatment. The purpose of treatment is to provide adequate neuronal decompression, providing stability, preservation of sagittal alignment and formation of bone fusion.

The aim of this study is to present the clinical experience and results in the application of atlantoaxial stabilization performed with Harms technique to contribute to the literature

\section{Methods}

This study was conducted with the approval of Ordu University Clinical Research Ethics Committee number 129.

Between January 2016 and January 2020, patients who were diagnosed with atlantoaxial instability in our clinic regardless of their etiology and applied screw fixation with Harm's technique were scanned and file data were obtained. All patients were evaluated in terms of complaints, diagnosis, preoperative and postoperative images, complications and fusion. Average follow up period is 24.6 months (6-48 months).

Patients with C1-2 screw fixation using the Harms technique and clinical follow-up data of at least 6 months were included in the study. Anterior route stabilization applications and patients with clinical follow-up less than 6 months were excluded from the study.

According to the clinical complaints, a suitable neck collar was worn to the patients who applied for trauma. Then all patients underwent cervical radiography, cervical computed tomography and cervical MRI examination. Angiography examination for the position of the vertebral artery was made in the preoperative period.

\section{Surgical Procedure}

Under general anesthesia, the prone position was taken to the operation with head holder. After cleaning and covering the surgical field; the skin was opened with a midline skin incision from the inion to the required cervical segment, then the paravertebral muscles were lateralized. C1 lateral mass and $\mathrm{C} 2$ pedicle screw were placed in accordance with the harm's technique with intraoperative fluoroscopy. Lateral mass screw was placed according to the Magerl technique planned to extend stabilization according to the level of lesion. Then, the system was stabilized with the help of cervical lordotic inclined rods.

Bone grafts were placed after the posterior elements were decorticated with the aid of a drill for fusion purposes, and the layers were closed anatomically.

All patients were evaluated for screw malposition and cervical alignment by pulling cervical CT on Day 1 after the operation. Preoperative Visual pain score (VAS) and Japanese Orthopedic Score (JOA) at 6th postoperative month were compared for clinical evaluation. Bone fusion was evaluated by dynamic radiographs and coronal sagittal plane CT examination at 6 th postoperative month. 


\section{Results}

Ten $(66.7 \%)$ of the 15 patients included in the study were male and $5(33.3 \%)$ were female. The average age was found to be $58.7(25-82)$. There were 6 patients $(40.0 \%)$ who had type 2 odontoid fracture according to Anderson and D'Alanzo classification, 2 patients $(13.3 \%)$ with Jefferson fracture, 2 patients (13.3\%) with C2 extension type tear drop fracture, 2 patients $(13.3 \%)$ with narrowing in the level of craniocervical junction, 1 patient $(6.7 \%)$ with upper cervical region tumor and 2 patient (13.3\%) was in the form of hangmans fracture. Patient distributions are given in Table 1. Two of our patients (13.3\%) had preoperative myelomalacia. Other patients did not have preoperative myelomalacia. Preoperative average JOA scores were 16.4 and average VAS scores were 7.2. There was no postoperative complication in all patients. No screw malposition was observed in the tomography examination performed in the postoperative period. Clinical worsening was not observed in any of our patients. It was observed in the postoperative 6th month followup that the JOA score increased by 17.8 and the VAS score decreased to 1.2. None of our patients had vertebral artery injuries and wound infection was not developed.

\section{Case Illustration (Case 13)}

Type 2 odontoid fracture was observed in the 81year-old female patient due to a traffic accident. In his neurological examination, the Glasgow coma scale was 15 points. There were no motor and sensory deficits. The patient underwent posterior C1-3 stabilization. No postoperative complications were seen. During the follow-up, the patient was discharged without any neurological disorders (Figure 1).

Table 1. Patient distributions

\begin{tabular}{|c|c|c|c|c|c|c|}
\hline $\begin{array}{l}\text { Case } \\
\text { No }\end{array}$ & Age & Sex & $\begin{array}{l}\text { Follow } \\
\text { Up }\end{array}$ & $\begin{array}{l}\text { Application } \\
\text { Reason }\end{array}$ & Diagnosis & $\begin{array}{l}\text { Stabilized } \\
\text { Segments }\end{array}$ \\
\hline 1 & 72 & Male & 15 & Falling from high & $\begin{array}{l}\text { C2 extension type tear drop fracture } \\
\text { Left C2 lamina fracture }\end{array}$ & $\mathrm{C} 1-3$ \\
\hline 2 & 80 & Female & 44 & Falling from high & Type 2 odontoid fracture & $\mathrm{C} 1-4$ \\
\hline 3 & 25 & Male & 40 & Firearm injury & Type 2 odontoid fracture & $\mathrm{C} 1-2$ \\
\hline 4 & 45 & Female & 42 & Neck pain & Recurrent cervical meningioma & $\mathrm{C} 1-3$ \\
\hline 5 & 64 & Male & 36 & Traffic accident & Jefferson fracture & $\mathrm{C} 1-2$ \\
\hline 6 & 49 & Male & 24 & Traffic accident & Jefferson fracture & $\mathrm{C} 1-2$ \\
\hline 7 & 33 & Male & 48 & Traffic accident & $\begin{array}{l}\text { C2 extension type tear drop fracture } \\
\text { Right } \mathrm{C} 1 \text { lateral mass fracture }\end{array}$ & $\mathrm{C} 1-3$ \\
\hline 8 & 47 & Female & 36 & Neck pain & Os odontoideum & $\mathrm{C} 1-2$ \\
\hline 9 & 71 & Male & 10 & Falling from high & $\begin{array}{l}\text { Hangman fracture } \\
\mathrm{C} 1 \text { anterior arch fracture } \\
\mathrm{C} 2 \text { cervical contusion }\end{array}$ & $\mathrm{C} 1-4$ \\
\hline 10 & 81 & Male & 11 & Falling from high & $\begin{array}{l}\text { Type } 2 \text { odontoid fracture } \\
\mathrm{C} 1 \text { anterior } \& \text { posterior arch fracture }\end{array}$ & $\mathrm{C} 1-3$ \\
\hline 11 & 82 & Male & 13 & Traffic accident & Type 2 odontoid fracture & $\mathrm{C} 1-2$ \\
\hline 12 & 73 & Male & 7 & Traffic accident & $\begin{array}{l}\text { Type } 2 \text { odontoid fracture } \\
\text { C5-6 spinous process fracture } \\
\text { C5-6 cervical contusion }\end{array}$ & $\mathrm{C} 1-7$ \\
\hline 13 & 81 & Female & 12 & Falling from high & Type 2 odontoid fracture & $\mathrm{C} 1-3$ \\
\hline 14 & 43 & Female & 25 & Neck pain & $\begin{array}{l}\text { Narrowing of the craniocervical junction, } \\
\text { Ankylosing spondylitis }\end{array}$ & $\mathrm{C} 1-5$ \\
\hline 15 & 40 & Male & 6 & Falling from high & $\begin{array}{l}\text { Hangman Fracture } \\
\text { C } 3 \text { corpus fracture }\end{array}$ & $\mathrm{C} 1-4$ \\
\hline
\end{tabular}




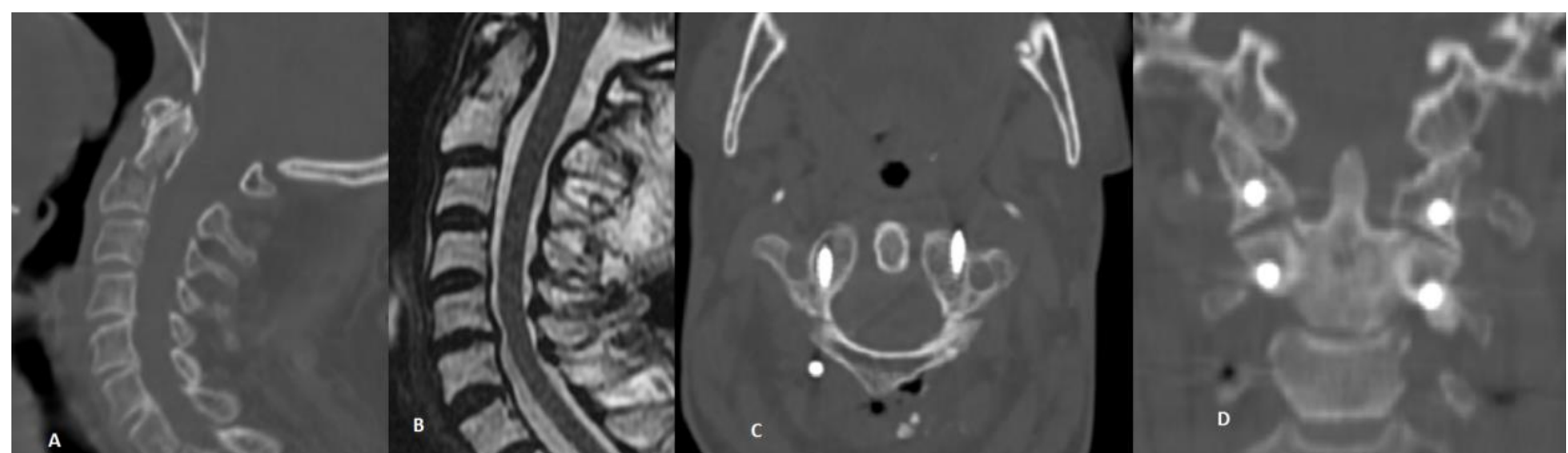

Figure 1: A: Sagittal CT image of Type 2 odontoid fracture, B: Preoperative T2 Cervical MR image, C: C1 lateral mass screw image on postoperative cervical CT axial plane, D: C1-2 lateral mass screw image on postoperative cervical CT coronal plane.

\section{Discussion}

Due to the complicated anatomical structure of the Atlas and axis and the location of the vertebral artery in this region, it makes the surgical treatment of the instability of the region difficult. Wiring fixation of C1-2, defined by Hadra in 1981, was used with various modifications (Gallie, 1939; Brooks et al.,1978; Coyne et al., 1995; Dickman et al., 1998). In order to reduce the neurological complications that may occur during wiring, interlaminary clamping known as halifax technique has been defined and developed as an apofix method by Honess and Back (Holness et al., 1984). However, it was observed that it was not sufficient especially in rotational stability (Huang et al., 2015). The C1-2 transarticular screw fixation technique defined by Magerl and Seeman in 1987 solved the fusion problem (Magerl and Seemann, 1987; Low and Redfern, 2002). However, it has been reported that spinal cord injury, vertebral artery injury, and hypoglossal nerve injury are observed in relation to this method (Dobran et al., 2016; Rajinda et al., 2017). This situation prompted researchers to develop methods with lower complication rates and higher fusion rates. Therefore, Goel and Laheri were first described as segmental screw flexion in 1994. In addition to the high fusion rate with this method, the risk of vertebral artery injury decreases, however, $\mathrm{C} 2$ root must be sacrificed during C1 lateral mass screw application (Goel and Lahari, 1994). Harms and Melcher showed that the root does not need to be sacrificed during screw application (Harms and Melcher, 2001). In this study, we used Harms technique to treat atlantoaxial instability of all our cases. In a study that conducted by Rajinda et al., in a series of 60 patients operated with $\mathrm{C} 1$ lateral mass and $\mathrm{C} 2$ pedicle screw fixation, 97\% fusion rate and significant improvement in VAS and JOA scores were reported (Rajinda et al., 2017). C2 ganglion was not required to be sacrificed in any of our patients. Neurological complications or vertebral artery injuries due to this method were not observed in any of our patients. Bone fusion in all our patients developed at 6 months. No neurological damage, vertebral or internal carotid artery injury were not observed due to $30 \mathrm{C} 1$ lateral mass, $30 \mathrm{C} 2$ pedicle screws, $36 \mathrm{C} 3-\mathrm{C} 6$ lateral mass and $2 \mathrm{C} 7$ pedicle screws that we used in the stabilization of our cases. Significant decrease in all VAS scores and increase in JOA scores was observed.

This study is conducted by a single neurosurgeon to contribute to the literature by using Harm's technique.

\section{Limitation}

This study is limited in several ways. The most significant limitation was the fact that the population of the study was a small group because upper cervical traumas are rarely seen incidents. This study is conducted by single surgeon and this is also another reason of the above mentioned limitation. In addition, there was no comparison with other techniques that defined to treat atlantoaxial instability.

\section{Conclusion}

Surgery of atlantoaxial instability is a pathology requiring adequate surgical experience due to the complicated anatomical structure. Using the Harms technique, sufficient stability is provided with a low complication rate. With this method, improvement in the clinical findings of the patients and high bone fusion are obtained. 
Ethics Committee Approval: This study was conducted with the approval of Ordu University Clinical Research Ethics Committee number 129.

Peer-review: Externally peer-reviewed.

Author Contributions: Concept- DOK, DesignDOK, Supervision- DOK, Analysis and/or Interpretation- DOK, Literature Review- DOK, Writing- DOK, Critical Review- DOK.

Conflict of Interest: No conflict of interest was declared by the authors.

Financial Disclosure: The authors declared that this study hasn't received no financial support.

\section{References}

Anderson LD, D' Alanzo R. Fractures of the odontoid proces of the axis. J Bone joint Surg Am 1974; 56: 1663-74.

Badhiwala JH, Nassiri F, Witiw CD, Mansouri A, Almenawer SA, Fehlings MG. Does Transection of the C2 Nerve Roots During C1 Lateral Mass Screw Placement for Atlantoaxial Fixation Result in a Superior Outcome? A Systematic Review of the Literature and Meta-analysis. Spine 2017; 42: E1067-76.

Brooks AL, Jenkins EB. Atlanto-axial arthrodesis by the wedge compression method. J Bone Joint Surg Am 60(3):279-284, 1978

Chen Q, Brahimaj BC, Khanna R, Kerolus MG, Tan LA, David B,et al. Posterior atlantoaxial fusion: a comprehensive review of surgical techniques and relevant vascular anomalies. J Spine Surg 2020; 6(1):164-180.

Coyne TJ, Fehlings MG, Wallace MC, Bernstein M, Tator CH. C1-C2 posterior cervical fusion: longterm evaluation of results and efficacy. Neurosurgery. 1995;37(4):688-693.

Caglar S. Aydin Z. Tuna H. Upper Cervical Region Traumas. in Aksoy K. (ed.) Basic Neurosurgery vol 2. Turkish Neurosurgery Association, Ankara, 2005, 1164-1173.

Dagtekin A, Kara E, Vayisoglu Y, Koseoglu A, Avci $\mathrm{E}$, Talas $\mathrm{D}$, et al. The importance of early diagnosis and appropriate treatment in Grisel's syndrome: report of two cases. Turk Neurosurg. 2011; 21(4):680-684.

Dickman CA, Sonntag VK. Posterior C1-C2 transarticular screw fixation for atlantoaxial arthrodesis. Neurosurgery. 1998;43(2):275-281.

Dobran M, Nasi D, Esposito DP, Iacoangeli M. Posterior Fixation with C1 Lateral Mass Screws and C2 Pars Screws for Type II Odontoid Fracture in the Elderly: Long-Term Follow-Up. World Neurosurg. 2016;96:152-158.
Gallie WE. Fractures and dislocations of the cervical spine. Am J Surg 1939; 46:495-499.

Goel A, Laheri V. Plate and screw fixation for atlanto-axial subluxation. Acta Neurochir (Wien). 1994;129(1-2):47-53.

Harms J, Melcher RP. Posterior C1-C2 fusion with polyaxial screw and rod fixation. Spine (Phila $\mathrm{Pa}$ 1976). 2001;26(22):2467-2471.

Holness RO, Huestis WS, Howes WJ, Langille RA. Posterior stabilization with an interlaminar clamp in cervical injuries: technical note and review of the long-term experience with the method. Neurosurgery. 1984;14(3):318-322.

Huang DG, Hao DJ, He BR, Wu QN, Liu TJ, Wang $\mathrm{XD}$, et al. Posterior atlantoaxial fixation: a review of all techniques. Spine J. 2015;15(10):22712281.

Kim DH, Hilibrand AS: Rheumatoid arthritis in the cervical spine. J Am Acad Orthop Surg 2005, 13(7):463-474.

Low HL, Redfern RM. C1-C2 transarticular screw fixation for atlantoaxial instability: a 6-year experience, and $\mathrm{C} 1-\mathrm{C} 2$ transarticular screw fixation-technical aspects. Neurosurgery. 2002;50(5):1165-1166.

Magerl F, Seemann PS. Stable posterior fusionof the atlas and axis by transarticular screw fixation. In: Kehr P, Weidner A (eds). Cervical Spine 1. New York: Springer-Verlag, 1987:322- 327

Isik HS, Sandal E, Cagli S. Clinical Outcomes of Posterior C1 and C2 Screw-Rod Fixation for Atlantoaxial Instability. Turk Neurosurg 2018; 28(4):602-609.

Rajinda P, Towiwat S, Chirappapha P. Comparison of outcomes after atlantoaxial fusion with $\mathrm{C} 1$ lateral mass-C2 pedicle screws and $\mathrm{C} 1-\mathrm{C} 2$ transarticular screws. Eur Spine J. 2017;26(4):1064-1072. 